\title{
Neonatal lipopolysaccharide exposure induces sexually dimorphic sickness behavior in adult rats
}

\author{
Maria M. Bernardi ${ }^{1}$, Lívia P. Teixeira ${ }^{1}$, Ana P. Ligeiro-de-Oliveira ${ }^{2}$, Wothan Tavares-de-Lima ${ }^{3}$, \\ João Palermo-Neto ${ }^{3}$, and Thiago B. Kirsten ${ }^{3}$ \\ 1. Universidade Paulista, São Paulo, SP, Brazil \\ 2. Universidade Nove de Julho, São Paulo, SP, Brazil \\ 3. Universidade de São Paulo, São Paulo, SP, Brazil
}

\begin{abstract}
The aim of the present study was to evaluate whether neonatal exposure to lipopolysaccharide (LPS; $50 \mu \mathrm{g} / \mathrm{kg}$, i.p., on postnatal day 2) induces depressive- and/or anxiety-like effects and sexually dimorphic responses in rats challenged with LPS $(100 \mu \mathrm{g} / \mathrm{kg}$, i.p.) in adulthood. The results revealed that males presented a less depressive state in the forced swim test and exhibited no changes in general motor activity in the open field test. Females exhibited an increase in sickness behavior, revealing different behavioral strategies in response to a bacterial disease. The male rats also exhibited higher cell proliferation, reflected by bone marrow and peripheral blood counts, and female rats exhibited a decrease in corticosterone levels. No changes were observed in the elevated plus maze or peripheral cytokine levels (interleukin-1 $\beta$ and tumor necrosis factor- $\alpha$ ). Neonatal exposure to LPS induced sexually dimorphic behavioral, neuroendocrine, and immune effects after an LPS challenge in adulthood, differentially affecting male and female susceptibility to disease later in life. Keywords: animal behavior, endotoxin, perinatal infection, proinflammatory cytokines, inflammatory mediators.
\end{abstract}

Received 02 September 2013; received in revised form 03 February 2014; accepted 05 February 2014. Available online 27 June 2014.

\section{Introduction}

Immune activation in early life has potentially long-term effects on the brain and behavior and can also affect the offspring's susceptibility to disease later in life (Rico, Ferraz, Ramalho-Pinto, \& Morato, 2010; Stoll et al., 2002; Stoll et al., 2004). For example, newborns with episodes of infection and who have impaired growth show adverse neurodevelopmental effects (Stoll et al., 2002).

Lipopolysaccharide (LPS), an endotoxin that mimics infection by Gram-negative bacteria, activates the immune system to release proinflammatory cytokines such as interleukin-1 $\beta$ (IL-1 $\beta$ ), tumor necrosis factor $\alpha$ (TNF- $\alpha$ ), and IL-6 (Aderem \& Ulevitch, 2000;

Maria Martha Bernardi and Lívia Pereira Teixeira, Health Sciences Institute, Paulista University. Ana Paula Ligeirode-Oliveira, Programa de Pós-graduação em Biofotônica Aplicada às Ciências da Saúde, Universidade Nove de Julho. Wothan Tavares-de-Lima, Department of Pharmacology, Biomedical Sciences Institute, University of São Paulo. João Palermo-Neto and Thiago Berti Kirsten, Department of Pathology, School of Veterinary Medicine, University of São Paulo. Correspondence regarding this article should be directed to: Maria Martha Bernardi, Health Sciences Institute, Paulista University, Rua Dr. Bacelar, 1212, São Paulo, SP, 04026-002, Brazil. E-mail: marthabernardi@gmail.com
Muller, Ziegler-Heitbrock, \& Baeuerle, 1993). These cytokines are considered to be mainly responsible for neurodevelopmental impairments (Hornig, Weissenbock, Horscroft, \& Lipkin, 1999; Pang, Cai, \& Rhodes, 2003; Shi, Fatemi, Sidwell, \& Patterson, 2003; $\mathrm{Yu}$, Yuan, Gu, \& Li, 2004) and the response to disease in adulthood (Boisse, Mouihate, Ellis, \& Pittman, 2004; Shanks et al., 2000) after infection/inflammation. Moreover, perinatal LPS exposure may result in sexually dimorphic effects. For example, prenatal treatment with LPS $(100 \mu \mathrm{g} / \mathrm{kg}$, intraperitoneally [i.p.], on gestational day [GD] 9.5) in rats impairs social behavior (play behavior) in both infancy and adulthood in male but not female offspring (Kirsten et al., 2012; Kirsten, Taricano, Maiorka, Palermo-Neto, \& Bernardi, 2010).

Few studies have examined the sexually dimorphic effects of immune system activation during the neonatal period on behavior and the immune response in adulthood. Tenk, Kavaliers, and Ossenkopp (2008) studied the effect of neonatal LPS administration on exploratory behavior in male and female rats after a challenge with LPS in adulthood. The authors reported increased susceptibility in male offspring in which adult males treated neonatally with LPS exhibited less activity in response to the LPS challenge compared with controls, an effect not observed in females (Tenk et al., 2008). Other recent studies have been published in this 
field (Tenk, Kavaliers, \& Ossenkopp, 2013; Wang et al., 2013).

According to the Global Burden of Disease Study, mood disorders such as depression and anxiety, are among the leading causes of disability worldwide (Kessler, 2000; Kessler \& Wittchen, 2000; Murray \& Lopez, 1997). It is estimated that over $15 \%$ of all adults will experience an episode of major depression (i.e., depressed mood, loss of interest or pleasure, feelings of guilt or low self-worth, disturbed sleep or appetite, low energy, and poor concentration) at some point in their lifetime, with more women affected than men (20\% vs. 10\%); (Kessler et al., 1994; Parker \& Brotchie, 2010). Similarly, it is estimated that $25 \%$ of the general population has suffered from an anxiety disorder (e.g., apprehensiveness, sense of impending danger, panic, increased heart rate, rapid breathing, sweating, trembling, and feeling weak or tired), and women are also more affected than men $(6.6 \%$ vs. 3.6\%); (Kessler, et al., 1994; Weisberg, 2009). The costs related to these diseases represent an economic burden of tens of billions of dollars per year (Jenkins \& Goldner, 2012).

Unfortunately, little is still known about the etiology and pathophysiology of depression and anxiety (Musselman, Evans, \& Nemeroff, 1998; Solomon et al., 2000). Smith (1991) proposed the macrophage theory of depression, which states that the excessive secretion of IL-1 and other products of macrophages is involved in the pathogenesis of depression. Anxiety also appears to be closely related to neuroimmune activation (Salim, Chugh, \& Asghar, 2012). Thus, the behavioral impairments, abnormal central monoamines, and hypothalamic-pituitary-adrenal (HPA) axis activation observed in depression and anxiety may be triggered by activation of the immune system, particularly during neurodevelopment (Anisman, 2009; Miller, Maletic, \& Raison, 2009; Salim, et al., 2012).

Because neonatal LPS exposure potentially induces sexually dimorphic effects and because depression and anxiety disorders can be triggered by immune activation and are more prevalent in women, the aim of the present study was to evaluate whether our rat model of neonatal exposure to LPS $(50 \mu \mathrm{g} / \mathrm{kg}$, i.p., on postnatal day [PND] 2) induces sexually dimorphic depressive- and/ or anxiety-like effects. To examine this possibility, we analyzed behavioral responses in the forced swim test, elevated plus maze, and open field in male and female offspring treated neonatally with LPS and challenged again with LPS (100 $\mu \mathrm{g} / \mathrm{kg}$, i.p.) in adulthood. Additionally, the total number of bone marrow cells, total and differential number of circulating leukocytes, serum and spleen levels of proinflammatory cytokines (IL-1 $\beta$ and TNF- $\alpha$ ), and serum levels of corticosterone were also studied in similarly treated rats. The LPS challenge was performed in adulthood because neural, behavioral, and immune changes after neonatal immune activation are best observed by inducing an immune challenge (Bilbo et al., 2005; 2008).

\section{Methods}

\section{Animals}

Twenty-six pregnant Wistar rats, 12-13 weeks of age and weighing 200-260 g, were used. The dams were individually housed in polypropylene cages $(38 \times 32$ $\times 16 \mathrm{~cm})$ with controlled temperature $\left(22 \pm 2^{\circ} \mathrm{C}\right)$ and humidity (45-65\%) and artificial lighting (12 h/12 h light/dark cycle; lights on at 6:00 AM). The animals had free access to Nuvilab rodent chow (Nuvital, São Paulo, SP, Brazil) and filtered water. Sterilized and residue-free wood shavings were used for the animal bedding. The dams were allowed to give birth normally and nurture their offspring. The day of birth was recorded as PND1. No handling was performed on PND1, but on PND2, eight offspring (four males and four females) were randomly selected for the following studies. No crossfostering procedures were used. Litters with fewer than eight pups were culled. The eight randomly selected pups remained with their dams until weaning on PND21. On PND21, the littermates were separated and co-housed by sex under the same conditions as their parents. The behavioral and immune experiments were performed with adult rats on PND60-70 treated neonatally with LPS or saline. The experimental design is described in Figure 1. One male and one female from each litter were used for each experiment, with different animals used in each experiment. All of the experiments were performed between 9:00 AM and 11:00 AM to minimize the possible influence of circadian changes, and the testing of the control and LPS-treated rats was intermixed. The animals used in this study were maintained in accordance with the guidelines of the Committee on the Care and Use of Laboratory Animal Resources of the School of Veterinary Medicine, University of São Paulo, Brazil (protocol no. 1398/2008, FMVZ - USP). These guidelines are based on those of the National Institutes of Health (Bethesda, MD, USA). The experiments were performed in accordance with good laboratory practice protocols and quality assurance methods.

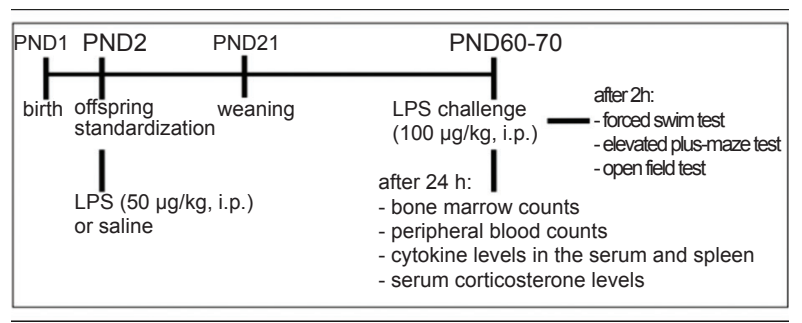

Figure 1. Experimental design. Male and female Wistar rats were treated with LPS on postnatal day (PND) 2 and PND6070. For the behavioral tests, different animals were used in each experiment. For the immune analyses, the same animals were used in each experiment.

\section{Treatment}

The animals were distributed into control (salinetreated) and experimental (LPS-treated) groups ( $n=13$ rats/group). Lipopolysaccharide (from Escherichia coli; 
Sigma, St. Louis, MO, USA; serotype 0127:B8) was dissolved in sterile saline $(50 \mu \mathrm{g} / \mathrm{ml}$ LPS in a $.9 \% \mathrm{NaCl}$ solution) and administered i.p. in male and female pups on PND2 at a dose of $50 \mu \mathrm{g} / \mathrm{kg}$. The neonatal LPS procedure was based on a previous study of sexually dimorphic exploratory effects (Tenk et al., 2008) and performed during a period of brain growth and maturation (Morgane, Mokler, \& Galler, 2002). The reason to specifically treat rats on PND2 was because the period immediately after birth in rodents is the last critical period for immune system development (Landreth, 2002).

The control groups consisted of male and female pups that received only sterile saline $(.9 \% \mathrm{NaCl})$ with the same treatment schedule as the LPS animals. Each control animal was treated with $.1 \mathrm{ml} / 10 \mathrm{~g}$ saline solution. Adult males and females in the control and LPS groups (total of four groups) were challenged with $100 \mu \mathrm{g} / \mathrm{kg}$ LPS, i.p., on PND60-70, 2 or $24 \mathrm{~h}$ before the tests (Tenk et al., 2008) as described below.

\section{Forced swim test}

The forced swim test, which evaluates "behavioral despair," is considered a useful method for depression research (Castagne, Moser, Roux, \& Porsolt, 2011; Porsolt, 1979). Fifty-two rats (13 from each group; i.e., males and females from the control and LPS groups) were evaluated in the forced swim test $2 \mathrm{~h}$ after the LPS challenge on PND60-70. The test was performed as previously described (Bernardi et al., 2010; Schwarz, Gorniak, Bernardi, Dagli, \& Spinosa, 2003). Briefly, in the adaptation session, the rats were individually placed in a glass cylinder ( $40 \mathrm{~cm}$ height, $22 \mathrm{~cm}$ diameter) that contained $25 \mathrm{~cm}$ of water at $20^{\circ} \mathrm{C}$. After 15 consecutive minutes in the cylinder, the animals were removed and allowed to dry for $30 \mathrm{~min}$ in a heated enclosure $\left(28^{\circ} \mathrm{C}\right)$ before being returned to their individual cages. One day later, in the test session, the rats were placed in the cylinder again, and the duration of immobility and latency to the first bout of immobility (in seconds) were measured during the following $5 \mathrm{~min}$. Immobility was operationally defined as the lack of active behaviors (i.e., struggling, swimming, and jumping), in which the rat remained passively floating or made only minimal movements that were necessary to maintain the nostrils above the water. The water in the cylinder was changed between sessions.

\section{Elevated plus maze}

The elevated plus maze is considered a useful method for anxiety research for the selective identification of anxiolytic and anxiogenic effects (Pellow, Chopin, File, \& Briley, 1985). Fifty-two rats (13 from each group; i.e., males and females from the control and LPS groups) were evaluated in the elevated plus maze $2 \mathrm{~h}$ after the LPS challenge on PND60-70. The test was performed as previously described (Kirsten, Taricano, Maiorka, et al., 2010). Briefly, the apparatus consisted of two opposing open arms (50 cm long, $10 \mathrm{~cm}$ wide) and two opposing closed arms $(50 \mathrm{~cm}$ long, $10 \mathrm{~cm}$ wide, and $40 \mathrm{~cm}$ high) arranged at $90^{\circ}$ angles. The floor of the maze was made of wood, painted gray (with an acrylic washable covering), and elevated $50 \mathrm{~cm}$ above the floor. The center of the maze was open, and the walls of the closed arms started $2 \mathrm{~cm}$ from the center of the maze. For the test, each animal was individually placed in the center of the maze with its head facing one of the open arms, and the following parameters were measured over a period of 5 min: number of entries into the arms, time spent in the open arms, number of entries into the closed arms, and time spent in the closed arms. The measure that reflects anxiety levels in this test is the percentage of time spent in the open arms (time in the open arms / [ time in the open arms + time in the closed arms] $\times$ 100 (Hogg, 1996). To preclude possible bias caused by odors left by previous rats, the apparatus was washed with a $5 \%$ alcohol/water solution before each session.

\section{General activity in the open field}

Fifty-two rats (13 from each group; i.e., males and females from the control and LPS groups) were used to assess general activity in the open field. The open field test evaluates exploratory/motor changes in rat behavior (Patti et al., 2005). General activity was analyzed as previously reported (Bernardi, Kirsten, Lago, Giovani, \& Massoco Cde, 2011). Briefly, $2 \mathrm{~h}$ after the LPS challenge on PND60-70, the rats were individually observed in the open field in 3-min sessions. The open field consisted of a round wooden arena $(96 \mathrm{~cm}$ diameter, $25 \mathrm{~cm}$-high walls) that was painted gray with an acrylic washable covering and subdivided into 25 parts. The measured parameters were the following: locomotion frequency (i.e., the number of floor sections entered with the four paws), rearing frequency (i.e., the number of times the animal stood on its hind legs), and immobility duration (i.e., the total time in seconds without spontaneous movement). The device was washed with a 5\% alcohol/water solution before placing each animal in the apparatus.

\section{Bone marrow counts}

Twenty-four rats (six from each group; i.e., males and females from the control and LPS groups) were used to quantify the total number of bone marrow cells in femoral marrow lavage fluid (Ligeiro-Oliveira et al., 2004). Briefly, $24 \mathrm{~h}$ after the LPS challenge, the left femur was removed under deep anesthesia with Rompum (Bayer, Shawnee Mission, KS, USA) + ketamine (ketamine hydrochloride Agener 10\%, União Química, Brazil; 1:1) intraperitoneally at a dose of $1.0 \mathrm{ml} / 300 \mathrm{~g}$ of animal body weight. All efforts were made to minimize the suffering of the animals. A needle that was connected to a plastic syringe and contained phosphate-buffered saline (PBS; $5 \mathrm{ml}$ ) was inserted into each femoral marrow to allow cell removal by flushing. The resultant femoral marrow lavage fluid was centrifuged at $170 \times g$ for $10 \mathrm{~min}$. The cell pellet was resuspended, processed, and analyzed for total 
leukocytes by adding $10 \mu \mathrm{l}$ Cresyl violet to $90 \mu \mathrm{l}$ of the cell suspension. The cells were counted under a light microscope in Neubauer chambers.

\section{Peripheral blood counts}

In the same rats from which the femoral marrow lavage fluid was collected (six rats from each group; i.e., males and females from the control and LPS groups), blood samples were taken from the abdominal aorta with plastic syringes that contained $50 \mu \mathrm{l}$ of $8 \%$ ethylenediaminetetraacetic acid (EDTA; Sigma, St. Louis, MO, USA) and subsequently diluted 1:20 in Turk's fluid (3\% acetic acid). The total number of cells was counted under a light microscope in Neubauer chambers. Differential leukocyte counts were performed on blood smears stained with May-Grünwald-Giemsa solution (Merck do Brazil SA, Sao Paulo, Brazil).

\section{Determination of cytokine levels in serum and spleen}

The spleens were removed from the same rats in which femoral marrow cell counts were made (six rats from each group; i.e., males and females from the control and LPS groups). The spleens were dissected to a volume of $5 \mathrm{ml}$ and placed on a glass dish that contained $10 \mathrm{ml}$ of RPMI-1640 culture medium (Sigma, St. Louis, MO, USA) supplemented with .5\% EDTA (Sigma, St. Louis, MO, USA). The spleens were then macerated, homogenized, and immediately centrifuged at $170 \times g$ for $10 \mathrm{~min}$ at $4^{\circ} \mathrm{C}$ with $3 \mathrm{ml}$ lysis buffer to remove the red blood cells from the homogenate. After centrifugation, the spleen supernatants were discharged, and the obtained cell pellets were resuspended in $1 \mathrm{ml}$ RPMI-1640 and plated $\left(1 \times 10^{6}\right.$ cells $\left./ \mathrm{ml}\right)$. After $24 \mathrm{~h}$, the supernatants were collected and stored at $-70^{\circ} \mathrm{C}$ until analysis.

Blood samples were also collected from the abdominal aortas of these anesthetized rats. The aliquots were centrifuged at $170 \times g$ for $10 \mathrm{~min}$, and the resulting serum was stored at $-70^{\circ} \mathrm{C}$ until analysis. This procedure allowed the detection of IL- $1 \beta$ and TNF- $\alpha$ levels in the serum samples and spleen supernatant. Cytokines were quantified using enzyme-linked immunosorbent (ELISA) kits (R\&D Systems, Minneapolis, MN, USA). Determinations were made in duplicate using standard curves according to the manufacturer's specifications. The results are expressed as $\mathrm{pg} / \mathrm{ml}$ of cytokine produced. The limits of detection were $31-2000 \mathrm{pg} / \mathrm{ml}$ for IL- $1 \beta$ and $31-1000 \mathrm{pg} / \mathrm{ml}$ for TNF- $\alpha$.

\section{Determination of serum corticosterone levels}

Using the same blood samples, serum corticosterone levels were determined using commercially available kits (Coat-a-Count; DPC, Los Angeles, CA, USA) as previously described (de Lima, Sakai, Latorre, Moreau, \& Palermo-Neto, 2010) and according to the manufacturer's instructions. Briefly, the procedure is based on a solid-phase radioimmunoassay in which ${ }^{125}$-labeled corticosterone competes with the corticosterone present in the sample for antibody sites over a fixed time interval. The serum samples were assayed directly without extraction or purification. The limit of corticosterone detection was $.011 \mathrm{pg} / \mathrm{ml}$.

\section{Statistical analyses}

The results are expressed as mean \pm SEM. Homoscedasticity was verified using Bartlett's test. Data were analyzed using two-way analysis of variance (ANOVA), followed by the Bonferroni post hoc test, with treatment and sex as factors. When no interaction was observed with the nonparametric data, the MannWhitney test was used to compare the data between groups. GraphPad Prism 5 software was used to analyze the data. In all cases, the results were considered significant at $p<.05$.

\section{Results}

Figure 2 shows that neonatal LPS exposure and adult LPS challenge reduced the duration of immobility in males but not females compared with their controls in the forced swim test. These results revealed a less depressive state in male rats that were neonatally exposed to LPS. The two-way ANOVA revealed a significant effect of treatment $\left(F_{1,48}=4.07, p=.049\right)$ but not sex $\left(F_{1,48}=.95, p=.334\right)$ and no interaction between factors $\left(F_{1,48}=1.70, p=.199\right.$; Figure $\left.2 \mathrm{~A}\right)$. The post hoc test showed a decrease in the duration of immobility in male rats compared with the respective control group. No differences were observed between the female groups. For the latency to the first episode of immobility, no effect of treatment $\left(F_{1,48}=1.64, p=.206\right)$ or $\operatorname{sex}\left(F_{1,48}\right.$ $=.08, p=.778)$ was found, with no interaction between factors $\left(F_{1,48}=2.80, p=.09\right.$; Figure $\left.2 \mathrm{~B}\right)$.
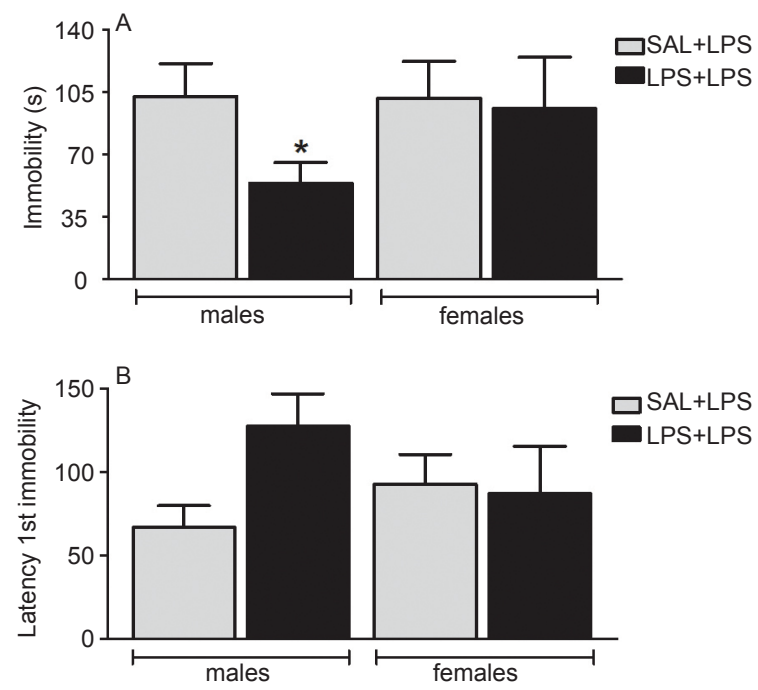

Figure 2. Effects of neonatal LPS exposure $(50 \mu \mathrm{g} / \mathrm{kg}$ on PND2) in the forced swim test in male and female rats after an LPS challenge on PND60-70. Fig. A- Immobility time (s). Fig.B- latency to first immobility (s). To both figures -gray bar, SAL+LPS group (neonatal saline and LPS challenge in adulthood); black bar, LPS+LPS group (neonatal LPS and LPS challenge in adulthood). $n=13$ rats/group. ${ }^{*} p<.05$, compared with corresponding control group (two-way ANOVA followed by Bonferroni test). The data are expressed as mean \pm SEM. 


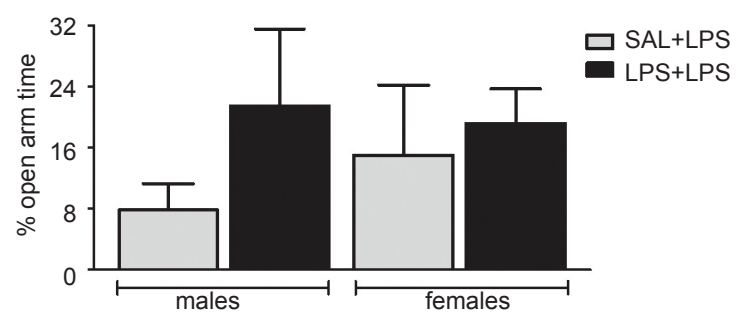

Figure 3. Effects of neonatal LPS exposure $(50 \mu \mathrm{g} / \mathrm{kg}$ on PND 2 ) in the elevated plus maze in male and female rats after an LPS challenge on PND60-70. Gray bar, SAL+LPS (control) group (neonatal saline and LPS challenge in adulthood); black bar, LPS+LPS group (neonatal LPS and LPS challenge in adulthood). $n=13$ rats/group. Data are expressed as mean \pm SEM (two-way ANOVA followed by Bonferroni test).

As shown in Figure 3, neonatal LPS exposure and adult LPS challenge did not affect the behavioral responses in the elevated plus maze in males or females. No differences were found in the number of entries into the open arms, time spent in the open arms, number of entries into the closed arms, or time spent in the closed arms (data not shown). Figure 3 also shows that the percent time in the open arms was also unaffected, with no effect of treatment $\left(F_{1,48}=1.48, p=.237\right)$ or $\operatorname{sex}\left(F_{1,48}\right.$ $=.11, p=.741)$ and no interaction between factors $\left(F_{1,48}\right.$ $=.41, p=.524)$.

For locomotion frequency, the two-way ANOVA revealed a significant effect of treatment $\left(F_{1,48}=4.05, p\right.$ $=.049)$ and significant interaction between factors $\left(F_{1,48}\right.$ $=5.80, p=.019)$ but no significant effect of $\operatorname{sex}\left(F_{1,48}=\right.$ $.54, p=.468$; Figure 4A). The post hoc test showed a decrease in locomotion in females in the experimental group $(p<.05)$. For rearing frequency, a significant interaction between factors was found $\left(F_{1,48}=10.30\right.$, $p=.024)$, with no effect of treatment $\left(F_{1,48}=1.26, p\right.$ $=.267)$ or $\operatorname{sex}\left(F_{1,48}=1.85, p=.180\right.$; Figure 4B). For the duration of immobility, a significant treatment effect was found $\left(F_{1,48}=4.58, p=.038\right)$ but no effect of sex $\left(F_{1,48}=.54, p=.84\right)$ and no interaction between factors $\left(F_{1,48}=2.07, p=.150\right.$; Figure $\left.4 C\right)$. The Mann-Whitney test showed an increase in immobility in females in the experimental group compared with the respective control group (Welch's approximated $t=2.91, d f=13$, $p=.012$ ). Thus, neonatal LPS exposure and adult LPS challenge impaired general activity in the open field in female experimental rats, in which the animals exhibited a decrease in locomotion and rearing frequencies and an increase in the duration of immobility. No differences were observed in male rats between groups. These results revealed a decrease in locomotor activity in females that were neonatally exposed to LPS.

For the number of bone marrow cells, the two-way ANOVA revealed significant effects of treatment $\left(F_{1,20}=\right.$ $32.12, p=.0001)$ and $\operatorname{sex}\left(F_{1,20}=303.16, p=.0001\right)$ and a significant interaction between factors $\left(F_{1,20}=15.13, p\right.$ $=.0009$; Figure 5$)$. The post hoc test showed an increase in the number of bone marrow cells in males but not females compared with their controls.
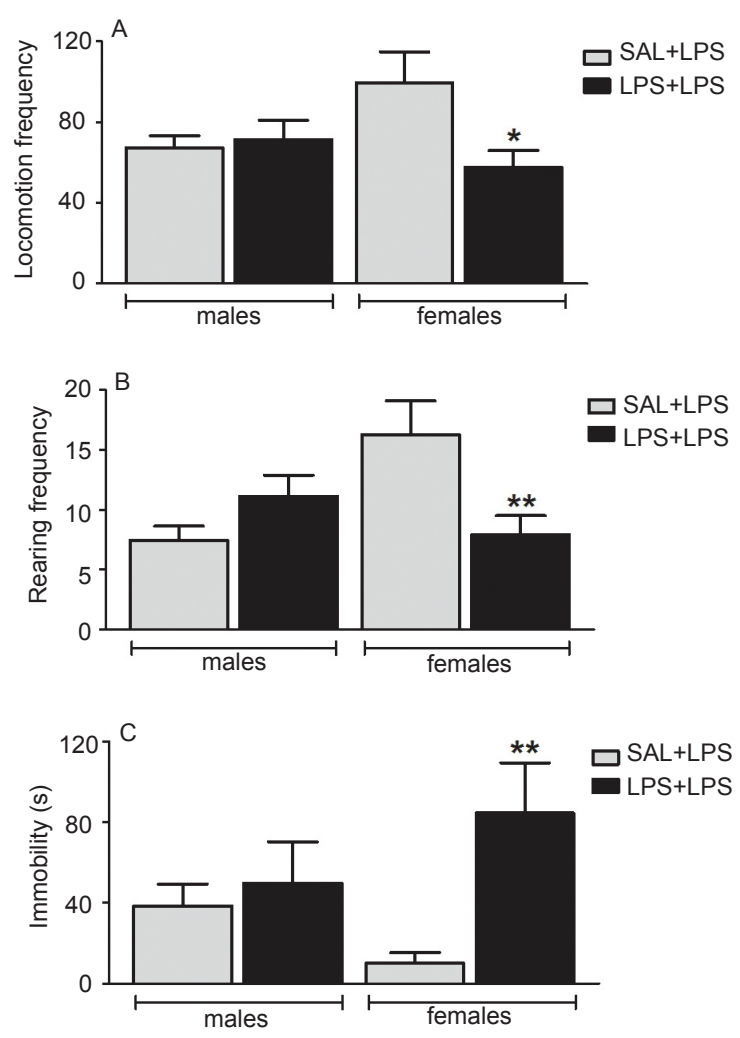

Figure 4. Effects of neonatal LPS exposure (50 $\mu \mathrm{g} / \mathrm{kg}$ on PND 2) in the open field in male and female rats after an LPS challenge on PND60-70. Fig.A- locomotion frequency; fig.B- Rearing frequency; Fig.C- Immobility duration (s). In both figs- gray bar, SAL+LPS group (neonatal saline and LPS challenge in adulthood); black bar, LPS+LPS group (neonatal LPS and LPS challenge in adulthood). $n=13$ rats/group. ${ }^{*} p<.05,{ }^{* *} p<.01$, compared with corresponding control group (two-way ANOVA followed by Bonferroni test). The data are expressed as mean \pm SEM.

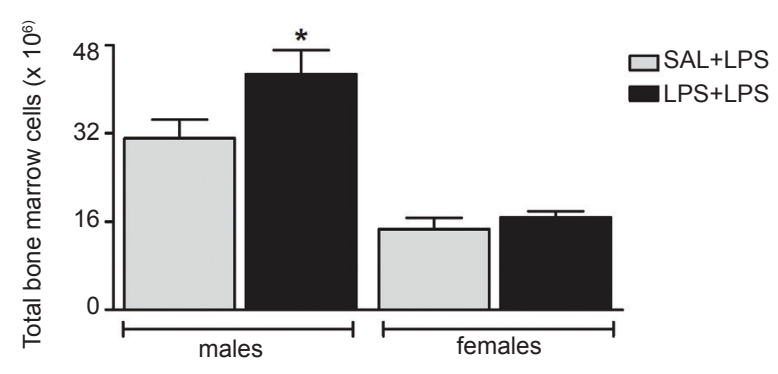

Figure 5. Effects of neonatal LPS exposure $(50 \mu \mathrm{g} / \mathrm{kg}$ on PND2) on the total number of bone marrow cells in male and female rats after an LPS challenge on PND 60-70. Gray bar, SAL+LPS (control) group (neonatal saline and LPS challenge in adulthood); black bar, LPS+LPS group (neonatal LPS and LPS challenge in adulthood). $n=6$ rats/group. ${ }^{*} p$ $<.05$, compared with corresponding control group (two-way ANOVA followed by Bonferroni test). The data are expressed as mean \pm SEM. 
For the total number of peripheral blood leukocytes, the two-way ANOVA revealed a significant effect of treatment $\left(F_{1,20}=14.04, p=.001\right)$ and an interaction between factors $\left(F_{1,20}=13.83, p=.001\right)$ but no effect of $\operatorname{sex}\left(F_{1,20}=3.69, p=.06\right.$; Figure $\left.6 \mathrm{~A}\right)$. The post hoc test indicated that neonatal LPS exposure and adult LPS challenge increased the total number of peripheral blood leukocytes in males but not females compared with controls $(p<.001)$. Similarly, the differential analysis showed that neonatal LPS exposure increased the number of polymorphonuclear and mononuclear cells in males but not females compared with their controls. For polymorphonuclear cells, a significant effect of treatment was found $\left(F_{1,20}=4.38, p=.049\right)$, with a significant interaction between factors $\left(F_{1,20}=5.70, p=\right.$ $.027)$ but no effect of $\operatorname{sex}\left(F_{1,20}=1.11, p=.305\right.$; Figure $6 \mathrm{~B})$. For mononuclear cells, no effect of treatment $\left(F_{1,20}\right.$ $=.04, p=.834)$ or $\operatorname{sex}\left(F_{1,20}=1.11, p=.079\right)$ was found, with no interaction between factors $\left(F_{1,20}=3.53, p=\right.$ .075; Figure 6C).
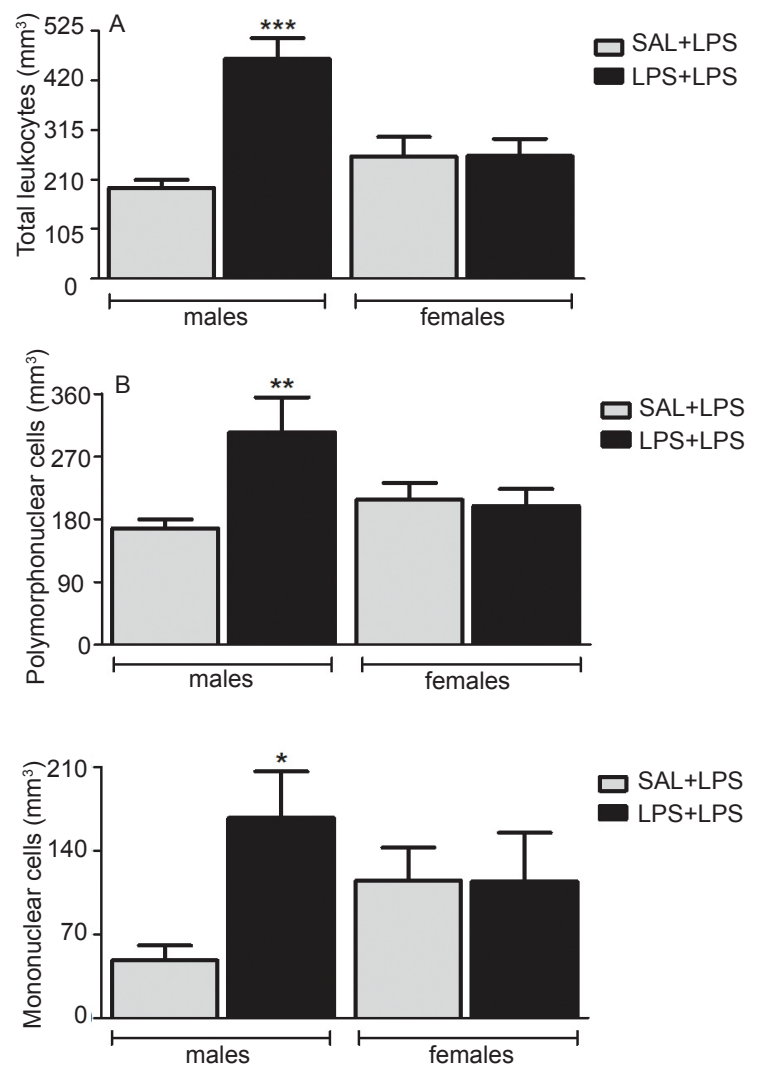

Figure 6. Effects of neonatal LPS exposure $(50 \mu \mathrm{g} / \mathrm{kg}$ on PND2) on the number of leukocytes and polymorphonuclear and mononuclear cells in peripheral blood in male and female rats after an LPS challenge on PND60-70. Gray bar, SAL+LPS (control) group (neonatal saline and LPS challenge in adulthood); black bar, LPS+LPS group (neonatal LPS and LPS challenge in adulthood). $n=6$ rats/group. $* p<.05, * * p$ $<.01, * * * p<.0001$, compared with corresponding control group (two-way ANOVA followed by Bonferroni test). The data are expressed as mean $\pm \mathrm{SEM}$.
Compared with their controls, males and females that were subjected to neonatal LPS exposure and adult LPS challenge exhibited no significant differences in serum and spleen IL- $1 \beta$ (Figure 7A) or TNF- $\alpha$ (Figure 7B) levels. For serum IL-1 $\beta$ levels, a significant effect of sex was found $\left(F_{1,15}=13.27, p=.0023\right)$, with no effect of treatment $\left(F_{1,15}=1.64, p=.220\right)$ and no interaction between factors $\left(F_{1,15}=.04, p=.841\right)$. For serum TNF- $\alpha$ levels, no significant effect of treatment $\left(F_{1,15}=3.92, p\right.$ $=.065)$ or $\operatorname{sex}\left(F_{1,15}=.01, p=.912\right)$ was found, with no interaction between factors $\left(F_{1,15}=.41, p=.532\right)$. For spleen IL-1 $\beta$ levels, no significant effect of treatment $\left(F_{1,20}=2.84, p=.107\right)$ or $\operatorname{sex}\left(F_{1,20}=2.78, p=.110\right)$ was found, with no interaction between factors $\left(F_{1,20}=3.03\right.$, $p=.097)$. For spleen TNF- $\alpha$ levels, no significant effect of treatment $\left(F_{1,20}=.60, p=.404\right)$ or $\operatorname{sex}\left(F_{1,20}=3.16\right.$, $p=.09)$ was found, with no interaction between factors $\left(F_{1,20}=15.26, p=.0009\right)$. The post-hoc test showed no differences between males and their controls, but females in the LPS group exhibited an increase in spleen TNF- $\alpha$ levels compared with their controls.
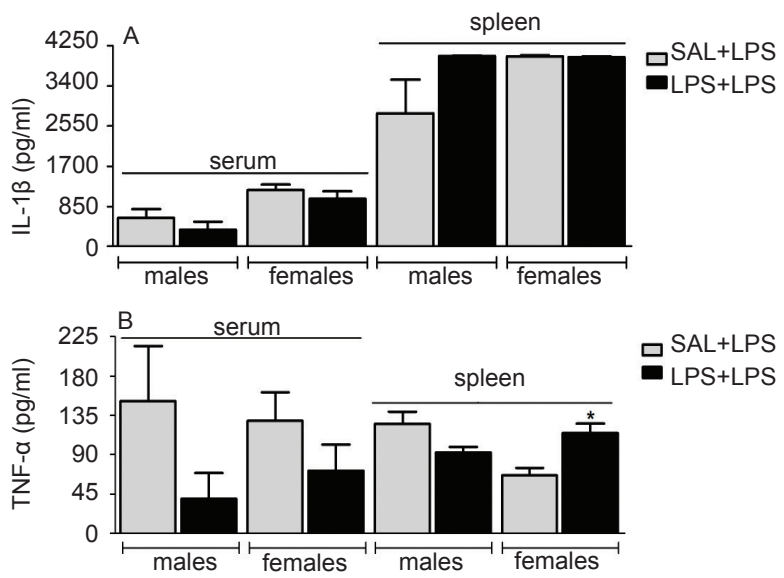

Figure 7. Effects of neonatal LPS exposure $(50 \mu \mathrm{g} / \mathrm{kg}$ on PND2) on serum and spleen cytokine (IL-1 $\beta$ and TNF- $\alpha$ ) levels in male and female rats after an LPS challenge on PND60-70. Gray bar, SAL+LPS (control) group (neonatal saline and LPS challenge in adulthood); black bar, LPS+LPS group (neonatal LPS and LPS challenge in adulthood). $n=4-6$ rats/group. ${ }^{*} p$ $<.05$, compared with corresponding control group (two-way ANOVA followed by Bonferroni test). The data are expressed as mean \pm SEM.

As shown in Figure 8, neonatal LPS exposure and adult LPS challenge reduced serum corticosterone levels in females but not males compared with their controls. The two-way ANOVA revealed significant effects of treatment $\left(F_{1,20}=9.77, p=.005\right)$ and $\operatorname{sex}\left(F_{1,20}=8.69\right.$, $p=.008)$ and a significant interaction between factors $\left(F_{1,20}=7.92, p=.01\right)$. Corticosterone levels in females in the LPS+LPS group were equivalent to the levels in both male groups. 


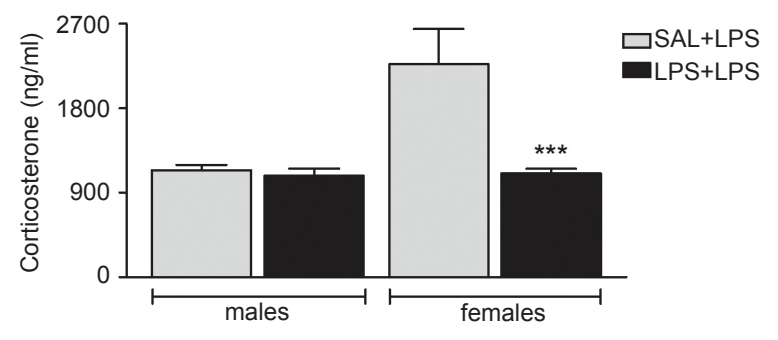

Figure 8. Effects of neonatal LPS exposure $(50 \mu \mathrm{g} / \mathrm{kg}$ on PND2) on serum corticosterone levels in male and female rats after an LPS challenge on PND60-70. Gray bar, SAL+LPS (control) group (neonatal saline and LPS challenge in adulthood); black bar, LPS+LPS group (neonatal LPS and LPS challenge in adulthood). $n=6$ rats/group. $* * * p<$ .0001 , compared with corresponding control group (two-way ANOVA followed by Bonferroni test). The data are expressed as mean \pm SEM.

\section{Discussion}

The present results showed that neonatal LPS exposure induced sexually dimorphic behavioral, neuroendocrine, and immune effects in rats after an LPS challenge in adulthood. Males but not females treated with LPS exhibited a less depressive state in the forced swim test. The forced swim test is considered a valid pharmacological tool to evaluate the depressive syndrome. It is based on the observation that rats initially move and try to escape from the water and subsequently remain motionless and float (Porsolt, Anton, Blavet, \& Jalfre, 1978). This posture was interpreted by Porsolt (1979) as a state of despair induced by an inescapable situation. The less depressive state of males in the present study might indicate the induction of endotoxin tolerance in response to neonatal LPS exposure. Endotoxin tolerance is defined as a state of reduced responsiveness to an endotoxin challenge after a primary bacterial insult (Yang et al., 2012). As an adaptive mechanism of the innate immune system, it protects the body against septic shock (Gantner \& Singh, 2007).

The mechanism of endotoxin tolerance is thought to involve the suppression of proinflammatory cytokine expression (Choi et al., 2011) and induction of long-term desensitization of the HPA axis after subsequent LPS exposure (Valles, Marti, Harbuz, \& Armario, 2002). Thus, the absence of a change in serum proinflammatory cytokine and corticosterone levels in males in the present study might be a consequence of endotoxin tolerance because cytokine and corticosterone levels would be expected to increase after an LPS challenge. Therefore, endotoxin tolerance appeared to prevent the increase in both serum proinflammatory cytokine and corticosterone levels.

The elevated plus maze is currently one of the most popular tests for anxiety (Pellow, et al., 1985). Its functionality as an animal model of anxiety is based on exploratory activity and the spontaneous natural aversion of rodents for open spaces. Our model of neonatal LPS exposure and LPS challenge in adulthood did not affect activity in the elevated plus maze. The procedure produced neither anxiolytic nor anxiogenic effects. Some studies reported that neonatal LPS exposure induced less anxietylike responses in the elevated plus maze (Rico, et al., 2010; Wang, et al., 2013), but the treatment protocol of these authors, including the postnatal day of injection, was different from the present study.

Neonatal exposure to LPS reduced general activity in the open field in female rats. The animals exhibited a decrease in locomotion and rearing frequencies and an increase in immobility duration, but these results were not observed in males. Hypoactivity is one of the best indices of sickness behavior induced by immune system activators, such as bacterial infections (Engeland, Kavaliers, \& Ossenkopp, 2003; Tenk, et al., 2008). Thus, the open field results indicated that female rats that were neonatally treated with LPS exhibited exacerbated sickness behavior when challenged with LPS in adulthood. Sickness behavior is considered an adaptive behavioral strategy that seeks to combat the invading organism and promote rapid healing (Hart, 1988; Kent, Bluthe, Kelley, \& Dantzer, 1992). The reduction of locomotor activity is adaptive because it decreases the chance of predation in the wild and conserves both energy and body heat, thereby facilitating fever production/maintenance and boosting immune function (Hart, 1988). The response in the open field test suggests that females but not males benefited from neonatal LPS exposure.

Neonatal LPS exposure also increased spleen TNF- $\alpha$ levels. Increased proinflammatory cytokine levels are another classic sign of sickness behavior (Kent et al., 1992). Thus, the peripheral cytokine levels observed in the present study supported the hypothesis that females exhibit an increase in sickness behavior. Spleen IL-1 $\beta$ levels and serum cytokine levels were not increased in the present study, likely because the immune evaluations were performed only $24 \mathrm{~h}$ after the LPS challenge. At the LPS dose used in the present study, the elevation of proinflammatory cytokine levels tends to stop after $12 \mathrm{~h}$ in rats (Gayle et al., 2004; Renaud et al., 2011).

According to the theory that sickness behavior is an adaptive strategy, the decrease in behavioral responsiveness to immune activation observed in females may be related to the risks associated with sickness during pregnancy (Avitsur \& Yirmiya, 1999). Infection during pregnancy increases the risk of spontaneous abortions, preterm labor, stillbirth, and neurodevelopmental impairments (Johnson, 1994; Lynch \& Ghidini, 1993). Thus, females that engage in sexual activity while sick may impair the chance of recovery and viability of the offspring (Avitsur \& Yirmiya, 1999). Lipopolysaccharide modified female behavior, working as a protective mechanism to reduce the chance of conception during an infection. 
In contrast to the present study, Tenk et al. (2008) showed that neonatal exposure to high-dose LPS on PND3 and PND5 decreased locomotor activity in the open field in male rats after an LPS challenge in adulthood, an effect not observed in females. Moreover, $50 \mu \mathrm{g} / \mathrm{kg}$ LPS on PND3 and PND5 was shown to increase the sensitivity of dopamine $\mathrm{D}_{2}$ receptors in male rats but not females (Walker et al., 2009). These discrepancies could be attributable to the different periods of neonatal LPS exposure and different doses used for the LPS challenge. The type of immunogen (e.g., LPS, polyriboinosinic-polyribocytidylic acid, and cytokines), dose, and time of administration (e.g., early vs. late gestation, neonatal period) may interact with sex and play significant roles in the observed variability (Rana, Aavani, \& Pittman, 2012).

Much evidence indicates that dopamine is involved in general activity in the open field (Bernardi, De Souza, \& Palermo Neto, 1981; Bernardi \& Neto, 1979; Carvalho et al., 2009; Fukushiro \& Frussa-Filho, 2011). Moreover, prenatal and neonatal LPS exposure may have long-term effects on the integrity of the dopamine system (Fan, Mitchell, Rhodes, \& Cai, 2008; Kirsten, et al., 2012; Kirsten, Taricano, Florio, Palermo-Neto, \& Bernardi, 2010; Tenk, Foley, Kavaliers, \& Ossenkopp, 2007). A neonatal intracerebral LPS injection was shown to damage the dopaminergic system (Fan et al., 2008) and enhance behavioral sensitization to the dopamine $\mathrm{D}_{2 / 3}$ receptor agonist quinpirole in adult female rats but not male rats (Tenk et al., 2007). Thus, the enhanced hypoactivity induced by LPS challenge observed only in female rats may have resulted from differential sensitivity of the dopaminergic system in male and female rats.

The likely reason that males did not present an increase in sickness behavior in the open field similarly to females is that sickness behavior is an induced motivational state that works differently in males and females (Avitsur \& Yirmiya, 1999). Employing a masculine strategy to increase reproductive success, male rodents tend to compete fiercely for access to mates and present a high tendency toward other risk-taking behavior associated with breeding (Zuk, 1990). Males may have developed these costly traits to indicate to the female that the male can "afford" this excessive burden (Avitsur \& Yirmiya, 1999). Thus, these masculine traits reveal the health status and resistance to parasites of the male, and females that choose mates according to these traits may gain the heritable benefits of disease resistance for their offspring (Zuk, 1990). Therefore, males cannot afford to display sickness behavior because they would not reproduce and perpetuate their genes. In other contexts, such as maintaining the social hierarchy, it is also important to mask sickness behavior to prevent status inferiority within the group (Avitsur, Cohen, \& Yirmiya, 1997; Yirmiya, Avitsur, Donchin, \& Cohen, 1995). The less depressive state in males that were neonatally exposed to LPS and subjected to the forced swim test corroborates the strategy of masking sickness behavior.

The behavioral expression of LPS-induced sickness behavior depends on the priority of the behavior under consideration (Aubert, Goodall, Dantzer, \& Gheusi, 1997). In situations where the animal is at risk of death or engaged in a hierarchical confrontation (e.g., with predators, competitors, and climatic extremes), sickness behavior is momentarily interrupted to prioritize behaviors, such as fight or flight or sexual and maternal behaviors (Aubert, 1999).

The sexually dimorphic behavior observed in neonatally LPS-exposed rats, regardless of whether sickness behavior was masked according to gender, corroborates the thrifty phenotype hypothesis. The thrifty phenotype hypothesis proposes that earlylife challenges promote specific adaptations in the developing organism, selecting appropriate responses to environmental cues (Wells, 2011). This developmental plasticity is also adaptive in the long-term and considered a manipulation of the offspring phenotype for their benefit (Wells, 2007). According to the thrifty phenotype hypothesis, males and females have different reproductive priorities and consequently different behavioral priorities.

We observed a decrease in serum corticosterone levels in females that were neonatally exposed to LPS and challenged with LPS compared with female controls. Although studies have reported that LPS elevated corticosterone production, the opposite may also occur. Several studies reported that rats exposed to LPS presented a decrease in corticosterone production, in Toll-like receptor 4, and adrenocorticotropic hormone receptor expression after a single LPS challenge, inducing long-term desensitization of the HPA axis (Liu et al., 2011; Valles, et al., 2002). Thus, we postulate that the decrease in corticosterone occurred because of an endotoxin tolerance process. Interestingly, when comparing males and females, serum corticosterone levels were higher in control females than in control males. This elevated level in females vs. males is a phenomenon that has been reported in several other studies (e.g., Garcia-Caceres et al., 2010; Bowman et al., 2004).

The immune analyses revealed that males but not females that were neonatally exposed to LPS and challenged with LPS presented higher cell proliferation (i.e., bone marrow cells, total leukocytes, and polymorphonuclear and mononuclear cells). This result was expected in males. In fact, in response to bacterial infection, the production of neutrophils by bone marrow is accelerated (Zhang et al., 2005) together with an increase in circulating leukocytes (Martin \& MatuteBello, 2011). However, explaining the increase in activation in the absence of an increase in the cytokine/ corticosterone response in males is difficult. Future studies may be conducted to better understand the mechanism of this profile of activated lymphocytes. 
The fact that females did not show these changes in cell proliferation is most likely attributable to a protective mechanism of estrogen. Laboratory studies showed that estrogen may affect the outcome following sepsis in which males are more susceptible than females (Diodato, Knoferl, Schwacha, Bland, \& Chaudry, 2001). Speyer et al. (2005) reported a protective effect of estrogen on the inflammatory response, in which IL-1 and IL-6 production and intercellular adhesion molecule-1 (ICAM-1) expression are reduced. ICAM1 is a member of the immunoglobulin superfamily and is critical for the firm arrest and transmigration of leukocytes out of blood vessels and into tissues. Its expression is increased by proinflammatory cytokines (Lawson \& Wolf, 2009).

In conclusion, neonatal exposure to LPS-induced sexually dimorphic behavioral, neuroendocrine, and immune effects after an LPS challenge in adult rats. Male rats exhibited a less depressive state and no changes in general locomotor activity, whereas female rats exhibited an increase in sickness behavior, revealing different behavioral strategies in response to a bacterial disease. Males most likely mask sickness behavior to increase their chances of reproduction and hierarchical status, and females preserve sickness behavior to avoid reproduction and consequent injuries, such as abortion. The immune system and HPA axis experiments also revealed sexual dimorphic effects in which males presented an increase in cell proliferation, and females presented a decrease in corticosterone levels. Thus, neonatal LPS exposure differentially affected disease susceptibility later in life in male and females.

\section{Acknowledgements}

This research was part of the Master's thesis of Lívia Pereira Teixeira, Curso de Pós-graduação em Imunopatologia Veterinária, Universidade Paulista. This research was sponsored by Fundação de Amparo à Pesquisa do Estado de São Paulo (FAPESP; thematic grant 09/51886-3) and CNPq.

\section{References}

Aderem, A., \& Ulevitch, R. J. (2000). Toll-like receptors in the induction of the innate immune response. Nature, 406(6797), 782-787.

Anisman, H. (2009). Cascading effects of stressors and inflammatory immune system activation: implications for major depressive disorder. Journal of Psychiatry \& Neuroscience, 34(1), 4-20.

Aubert, A. (1999). Sickness and behaviour in animals: a motivational perspective. Neuroscience \& Biobehavioral Reviews, 23(7), 1029-1036.

Aubert, A., Goodall, G., Dantzer, R., \& Gheusi, G. (1997). Differential effects of lipopolysaccharide on pup retrieving and nest building in lactating mice. Brain Behav Immun, 11(2), 107-118.

Avitsur, R., Cohen, E., \& Yirmiya, R. (1997). Effects of interleukin-1 on sexual attractivity in a model of sickness behavior. Physiol Behav, 63(1), 25-30.

Avitsur, R., \& Yirmiya, R. (1999). The immunobiology of sexual behavior: gender differences in the suppression of sexual activity during illness. Pharmacol Biochem Behav, 64(4), 787-796.

Bernardi, M. M., De Souza, H., \& Palermo Neto, J. (1981). Effects of single and long-term haloperidol administration on open field behavior of rats. Psychopharmacology (Berl), 73(2), 171-175.
Bernardi, M. M., Kirsten, T. B., Lago, J. H., Giovani, T. M., \& Massoco Cde, O. (2011). Nepeta cataria L. var. citriodora (Becker) increases penile erection in rats. Journal of Ethnopharmacology, 137(3), 1318-1322.

Bernardi, M. M., Kirsten, T. B., Salzgeber, S. A., Ricci, E. L., Romoff, P., Lago, J. H. G., \& Lourenço, L. M. (2010). Antidepressant-like effects of an apolar extract and chow enriched with Nepeta cataria (catnip) in mice. Psychology \& Neuroscience, 3(2), 251-258.

Bernardi, M. M., \& Neto, J. P. (1979). Effects of abrupt and gradual withdrawal from long-term haloperidol treatment on open field behavior of rats. Psychopharmacology (Berl), 65(3), 247-250.

Bilbo, S. D., Barrientos, R. M., Eads, A. S., Northcutt, A., Watkins, L. R., Rudy, J. W., \& Maier, S. F. (2008). Early-life infection leads to altered BDNF and IL-1beta mRNA expression in rat hippocampus following learning in adulthood. Brain Behavior and Immunity, 22(4), 451-455.

Bilbo, S. D., Biedenkapp, J. C., Der-Avakian, A., Watkins, L. R., Rudy, J. W., \& Maier, S. F. (2005). Neonatal infection-induced memory impairment after lipopolysaccharide in adulthood is prevented via caspase-1 inhibition. Journal of Neuroscience, 25(35), 8000-8009.

Boisse, L., Mouihate, A., Ellis, S., \& Pittman, Q. J. (2004). Long-term alterations in neuroimmune responses after neonatal exposure to lipopolysaccharide. Journal of Neuroscience, 24(21), 4928-4934.

Bowman, R. E., MacLusky, N. J., Sarmiento, Y., Frankfurt, M., Gordon, M., \& Luine, V. N. (2004). Sexually dimorphic effects of prenatal stress on cognition, hormonal responses, and central neurotransmitters. Endocrinology, 145(8), 3778-3787.

Carvalho, R. C., Fukushiro, D. F., Helfer, D. C., Callegaro-Filho, D., Trombin, T. F., Zanlorenci, L. H. ... \& Frussa-Filho, R. (2009). Long-term haloperidol treatment (but not risperidone) enhances addiction-related behaviors in mice: role of dopamine D2 receptors. Addiction Biology, 14(3), 283-293.

Castagne, V., Moser, P., Roux, S., \& Porsolt, R. D. (2011). Rodent models of depression: forced swim and tail suspension behavioral despair tests in rats and mice. Curr Protoc Neurosci, Chapter 8, Unit 8 10A.

Choi, E. J., Lee, S., Chae, J. R., Lee, H. S., Jun, C. D., \& Kim, S. H. (2011). Eupatilin inhibits lipopolysaccharide-induced expression of inflammatory mediators in macrophages. Life Sciences, 88(25-26), $1121-1126$

de Lima, C. B., Sakai, M., Latorre, A. O., Moreau, R. L., \& PalermoNeto, J. (2010). Effects of different doses and schedules of diazepam treatment on lymphocyte parameters in rats. International Immunopharmacology, 10(11), 1335-1343.

Diodato, M. D., Knoferl, M. W., Schwacha, M. G., Bland, K. I., \& Chaudry, I. H. (2001). Gender differences in the inflammatory response and survival following haemorrhage and subsequent sepsis. Cytokine, 14(3), 162-169.

Engeland, C. G., Kavaliers, M., \& Ossenkopp, K. P. (2003). The influence of photoperiod and sex on lipopolysaccharide-induced hypoactivity and behavioral tolerance development in meadow voles (Microtus pennsylvanicus). Psychoneuroendocrinology, 28(8), 970-991.

Fan, L. W., Chen, R. F., Mitchell, H. J., Lin, R. C., Simpson, K. L., Rhodes, P. G., \& Cai, Z. (2008). alpha-Phenyl-n-tert-butylnitrone attenuates lipopolysaccharide-induced brain injury and improves neurological reflexes and early sensorimotor behavioral performance in juvenile rats. Journal of Neuroscience Research, 86(16), 3536-3547.

Fan, L. W., Mitchell, H. J., Rhodes, P. G., \& Cai, Z. (2008). AlphaPhenyl-n-tert-butyl-nitrone attenuates lipopolysaccharide-induced neuronal injury in the neonatal rat brain. Neuroscience, 151(3), 737-744.

Fukushiro, D. F., \& Frussa-Filho, R. (2011). Chronic amphetamine transforms the emotional significance of a novel but not a familiar environment: implications for addiction. International Journal of Neuropsychopharmacology, 14(7), 955-965.

Gantner, B. N., \& Singh, H. (2007). Immunology: Short-term memory. Nature, 447(7147), 916-917.

Garcia-Caceres, C., Lagunas, N., Calmarza-Font, I., Azcoitia, I., Diz-Chaves, Y., Garcia-Segura, L. M. ... \& Chowen, J. A. (2010). Gender differences in the long-term effects of chronic prenatal stress on the HPA axis and hypothalamic structure in rats. Psychoneuroendocrinology, 35(10), 1525-1535. 
Gayle, D. A., Beloosesky, R., Desai, M., Amidi, F., Nunez, S. E., \& Ross, M. G. (2004). Maternal LPS induces cytokines in the amniotic fluid and corticotropin releasing hormone in the fetal rat brain. Am J Physiol Regul Integr Comp Physiol, 286(6), R1024-1029.

Hart, B. L. (1988). Biological basis of the behavior of sick animals. Neurosci Biobehav Rev, 12(2), 123-137.

Hogg, S. (1996). A review of the validity and variability of the elevated plus-maze as an animal model of anxiety. Pharmacology Biochemistry and Behavior, 54(1), 21-30.

Hornig, M., Weissenbock, H., Horscroft, N., \& Lipkin, W. I. (1999). An infection-based model of neurodevelopmental damage. Proc Natl Acad Sci U S A, 96(21), 12102-12107.

Jenkins, E., \& Goldner, E. M. (2012). Approaches to understanding and addressing treatment-resistant depression: a scoping review. Depress Res Treat, 2012, 469680.

Johnson, R. T. (1994). Infections during pregnancy. Advances in Neurology, 64, 153-162.

Kent, S., Bluthe, R. M., Kelley, K. W., \& Dantzer, R. (1992). Sickness behavior as a new target for drug development. Trends Pharmacol Sci, 13(1), 24-28.

Kessler, R. C. (2000). The epidemiology of pure and comorbid generalized anxiety disorder: a review and evaluation of recent research. Acta Psychiatr Scand Suppl(406), 7-13.

Kessler, R. C., McGonagle, K. A., Zhao, S., Nelson, C. B., Hughes, M., Eshleman, S., Wittchen, H. U., \& Kendler, K. S. (1994). Lifetime and 12-month prevalence of DSM-III-R psychiatric disorders in the United States. Results from the National Comorbidity Survey. Archives of General Psychiatry, 51(1), 8-19.

Kessler, R. C., \& Wittchen, H. U. (2000). Anxiety and depression: the impact of shared characteristics on diagnosis and treatment. Introduction. Acta Psychiatr Scand Suppl(406), 5-6.

Kirsten, T. B., Chaves-Kirsten, G. P., Chaible, L. M., Silva, A. C., Martins, D. O., Britto, L. R. ... \& Bernardi, M. M. (2012). Hypoactivity of the central dopaminergic system and autisticlike behavior induced by a single early prenatal exposure to lipopolysaccharide. Journal of Neuroscience Research, 90(10), 1903-1912.

Kirsten, T. B., Taricano, M., Florio, J. C., Palermo-Neto, J., \& Bernardi, M. M. (2010). Prenatal lipopolysaccharide reduces motor activity after an immune challenge in adult male offspring. Behavioural Brain Research, 211(1), 77-82.

Kirsten, T. B., Taricano, M., Maiorka, P. C., Palermo-Neto, J., \& Bernardi, M. M. (2010). Prenatal lipopolysaccharide reduces social behavior in male offspring. Neuroimmunomodulation, 17(4), 240-251.

Landreth, K. S. (2002). Critical windows in development of the rodent immune system. Human \& Experimental Toxicology, 21(9-10), 493-498.

Lawson, C., \& Wolf, S. (2009). ICAM-1 signaling in endothelial cells. Pharmacol Rep, 61(1), 22-32.

Ligeiro-Oliveira, A. P., Fialho de Araujo, A. M., Lazzarini, R., Silva, Z. L., De Nucci, G., Muscara, M. N. ... \& Palermo-Neto, J. (2004). Effects of amphetamine on immune-mediated lung inflammatory response in rats. Neuroimmunomodulation, 11(3), 181-190.

Liu, S., Zhu, X., Liu, Y., Wang, C., Wang, S., Tang, X., \& Ni, X. (2011). Endotoxin tolerance of adrenal gland: attenuation of corticosterone production in response to lipopolysaccharide and adrenocorticotropic hormone. Crit Care Med, 39(3), 518-526.

Lynch, L., \& Ghidini, A. (1993). Perinatal infections. Curr Opin Obstet Gynecol, 5(1), 24-32.

Martin, T. R., \& Matute-Bello, G. (2011). Experimental models and emerging hypotheses for acute lung injury. Crit Care Clin, 27(3), 735-752.

Miller, A. H., Maletic, V., \& Raison, C. L. (2009). Inflammation and its discontents: the role of cytokines in the pathophysiology of major depression. Biological Psychiatry, 65(9), 732-741.

Morgane, P. J., Mokler, D. J., \& Galler, J. R. (2002). Effects of prenatal protein malnutrition on the hippocampal formation. Neuroscience \& Biobehavioral Reviews, 26(4), 471-483.

Muller, J. M., Ziegler-Heitbrock, H. W., \& Baeuerle, P. A. (1993). Nuclear factor kappa B, a mediator of lipopolysaccharide effects. Immunobiology, 187(3-5), 233-256.
Murray, C. J., \& Lopez, A. D. (1997). Global mortality, disability, and the contribution of risk factors: Global Burden of Disease Study. Lancet, 349(9063), 1436-1442.

Musselman, D. L., Evans, D. L., \& Nemeroff, C. B. (1998). The relationship of depression to cardiovascular disease: epidemiology, biology, and treatment. Archives of General Psychiatry, 55(7), 580-592.

Pang, Y., Cai, Z., \& Rhodes, P. G. (2003). Disturbance of oligodendrocyte development, hypomyelination and white matter injury in the neonatal rat brain after intracerebral injection of lipopolysaccharide. Brain Res Dev Brain Res, 140(2), 205-214.

Parker, G., \& Brotchie, H. (2010). Gender differences in depression. International Review of Psychiatry, 22(5), 429-436.

Patti, C. L., Frussa-Filho, R., Silva, R. H., Carvalho, R. C., Kameda, S. R., Takatsu-Coleman, A. L., Cunha, J. L., \& Abilio, V. C. (2005). Behavioral characterization of morphine effects on motor activity in mice. Pharmacology Biochemistry and Behavior, 81(4), 923-927.

Pellow, S., Chopin, P., File, S. E., \& Briley, M. (1985). Validation of open:closed arm entries in an elevated plus-maze as a measure of anxiety in the rat. Journal of Neuroscience Methods, 14(3), 149-167.

Porsolt, R. D. (1979). Animal model of depression. Biomedicine, 30(3), 139-140.

Porsolt, R. D., Anton, G., Blavet, N., \& Jalfre, M. (1978). Behavioural despair in rats: a new model sensitive to antidepressant treatments. European Journal of Pharmacology, 47(4), 379-391.

Rana, S. A., Aavani, T., \& Pittman, Q. J. (2012). Sex effects on neurodevelopmental outcomes of innate immune activation during prenatal and neonatal life. Hormones and Behavior, 62(3), 228-236.

Renaud, S. J., Cotechini, T., Quirt, J. S., Macdonald-Goodfellow, S. K., Othman, M., \& Graham, C. H. (2011). Spontaneous pregnancy loss mediated by abnormal maternal inflammation in rats is linked to deficient uteroplacental perfusion. Journal of Immunology, 186(3), 1799-1808.

Rico, J. L., Ferraz, D. B., Ramalho-Pinto, F. J., \& Morato, S. (2010). Neonatal exposure to LPS leads to heightened exploratory activity in adolescent rats. Behavioural Brain Research, 215(1), 102-109.

Salim, S., Chugh, G., \& Asghar, M. (2012). Inflammation in anxiety. Adv Protein Chem Struct Biol, 88, 1-25.

Schwarz, A., Gorniak, S. L., Bernardi, M. M., Dagli, M. L., \& Spinosa, H. S. (2003). Effects of Ipomoea carnea aqueous fraction intake by dams during pregnancy on the physical and neurobehavioral development of rat offspring. Neurotoxicol Teratol, 25(5), 615-626.

Shanks, N., Windle, R. J., Perks, P. A., Harbuz, M. S., Jessop, D. S., Ingram, C. D., \& Lightman, S. L. (2000). Early-life exposure to endotoxin alters hypothalamic-pituitary-adrenal function and predisposition to inflammation. Proceedings of the National Academy of Sciences of the United States of America, 97(10), 5645-5650.

Shi, L., Fatemi, S. H., Sidwell, R. W., \& Patterson, P. H. (2003). Maternal influenza infection causes marked behavioral and pharmacological changes in the offspring. J Neurosci, 23(1), 297-302.

Smith, R. S. (1991). The macrophage theory of depression. Medical Hypotheses, 35(4), 298-306.

Solomon, D. A., Keller, M. B., Leon, A. C., Mueller, T. I., Lavori, P. W., Shea, M. T. ... \& Endicott, J. (2000). Multiple recurrences of major depressive disorder. American Journal of Psychiatry, 157(2), 229-233.

Speyer, C. L., Rancilio, N. J., McClintock, S. D., Crawford, J. D., Gao, H., Sarma, J. V., \& Ward, P. A. (2005). Regulatory effects of estrogen on acute lung inflammation in mice. American Journal of Physiology - Cell Physiology, 288(4), C881-890.

Stoll, B. J., Hansen, N., Fanaroff, A. A., Wright, L. L., Carlo, W. A., Ehrenkranz, R. A. ... \& Poole, W. K. (2002). Late-onset sepsis in very low birth weight neonates: the experience of the NICHD Neonatal Research Network. Pediatrics, 110(2 Pt 1), 285-291.

Stoll, B. J., Hansen, N. I., Adams-Chapman, I., Fanaroff, A. A., Hintz, S. R., Vohr, B., \& Higgins, R. D. (2004). Neurodevelopmental and growth impairment among extremely low-birth-weight infants with neonatal infection. JAMA, 292(19), 2357-2365.

Tenk, C. M., Foley, K. A., Kavaliers, M., \& Ossenkopp, K. P. (2007). Neonatal immune system activation with lipopolysaccharide enhances behavioural sensitization to the dopamine agonist, quinpirole, in adult female but not male rats. Brain Behavior and Immunity, 21(7), 935-945. 
Neonatal LPS and sickness behavior

123

Tent, C. M., Kavaliers, M., \& Ossenkopp, K. P. (2008). Sexually dimorphic effects of neonatal immune system activation with lipopolysaccharide on the behavioural response to a homotypic adult immune challenge. International Journal of Developmental Neuroscience, 26(3-4), 331-338.

Tent, C. M., Kavaliers, M., \& Ossenkopp, K. P. (2013). Neonatal treatment with lipopolysaccharide differentially affects adult anxiety responses in the light-dark test and taste neophobia test in male and female rats. International Journal of Developmental Neuroscience, 31(3), 171-180.

Vales, A., Marti, O., Harbuz, M. S., \& Armario, A. (2002). A single lipopolysaccharide administration is sufficient to induce a longterm desensitization of the hypothalamic-pituitary-adrenal axis. Neuroscience, 112(2), 383-389.

Walker, A. K., Nakamura, T., Byrne, R. J., Naicker, S., Tynan, R. J., Hunter, M., \& Hodgson, D. M. (2009). Neonatal lipopolysaccharide and adult stress exposure predisposes rats to anxiety-like behaviour and blunted corticosterone responses: implications for the double-hit hypothesis. Psychoneuroendocrinology, 34(10), 1515-1525.

Wang, K. C., Fan, L. W., Kaizaki, A., Pang, Y., Cai, Z., \& Tien, L. T. (2013). Neonatal lipopolysaccharide exposure induces long-lasting learning impairment, less anxiety-like response and hippocampal injury in adult rats. Neuroscience, 234, 146-157.
Weisberg, R. B. (2009). Overview of generalized anxiety disorder: epidemiology, presentation, and course. Journal of Clinical Psychiatry, 70 Suppl 2, 4-9.

Wells, J. C. (2007). The thrifty phenotype as an adaptive maternal effect. Biological Reviews of the Cambridge Philosophical Society, 82(1), 143-172.

Wells, J. C. (2011). The thrifty phenotype: An adaptation in growth or metabolism? American Journal of Human Biology, 23(1), 65-75.

Yang, Y., Sun, H., Mo, X., Lu, Y., JiG, H., Li, X., Chang, G., \& Li, Q. (2012). Prediction of novel genes associated with negative regulators of toll-like receptors-induced inflammation based on endotoxin tolerance. Inflammation, 35(6), 1889-1899.

Yirmiya, R., Avitsur, R., Donchin, O., \& Cohen, E. (1995). Interleukin-1 inhibits sexual behavior in female but not in male rats. Brain Behavior and Immunity, 9(3), 220-233.

Yo, H. M., Yuan, T. M., Gu, W. Z., \& Li, J. P. (2004). Expression of glia fibrillary acidic protein in developing rat brain after intrauterine infection. Neuropathology, 24(2), 136-143.

Chang, P., Quinton, L. J., Gamble, L., Bagby, G. J., Summer, W. R., \& Nelson, S. (2005). The granulopoietic cytokine response and enhancement of granulopoiesis in mice during endotoxemia. Shock, 23(4), 344-352.

Zuk, M. (1990). Reproductive strategies and disease susceptibility: an evolutionary viewpoint. Parasitology Today, 6(7), 231-233. 